\title{
Correction: TGLI1 transcription factor mediates breast cancer brain metastasis via activating metastasis-initiating cancer stem cells and astrocytes in the tumor microenvironment
}

\author{
Sherona R. Sirkisoon - Richard L. Carpenter - Tadas Rimkus - Daniel Doheny - Dongqin Zhu - Noah R. Aguayo • \\ Fei Xing · Michael Chan · Jimmy Ruiz · Linda J. Metheny-Barlow · Roy Strowd • Jiayuh Lin · Angelina T. Regua • \\ Austin Arrigo - Marlyn Anguelov $\cdot$ Boris Pasche (1) - Waldemar Debinski $\cdot$ Kounosuke Watabe $\cdot$ Hui-Wen Lo
}

Published online: 2 March 2021

(c) The Author(s), under exclusive licence to Springer Nature Limited 2021
It was also noted that the source of a cell line was incorrectly stated (page 77; Materials and Methods; first paragraph; 2nd sentence).

This has been corrected to read

"The brain metastatic cell line (SKBRM) and radioresistant cell lines (SKBRM-RR and 231BRM-RR) were kind gifts from Drs. Fei Xing and Kounosuke Watabe; E6/ E7/hTERT immortalized human astrocytes were kind gifts from Dr. Russell Pieper (University of California-San Francisco)."

This has been corrected in the HTML and PDF versions of the article.
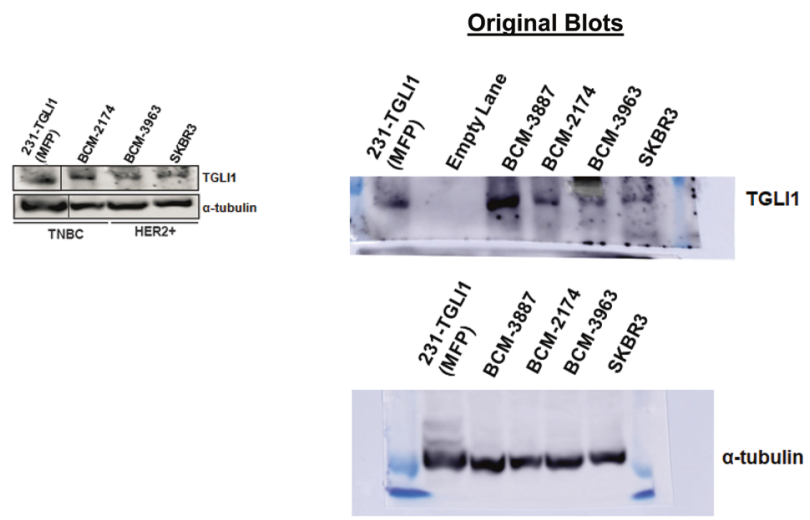

Fig. 1c Expression of TGLI1 in MDA-MB-231-TGLI1 mammary fat pad (MFP) xenograft was similar to that found in two breast cancer PDXs, BCM-2174 and BCM-3963. TNBC, triple-negative breast cancer. Western blots were conducted using the TGLI1-specific antibody and a tubulin antibody. Left: western blots. Right: original western blot images. 